\title{
Recovery of Paleodictyon patterns after simulated mining activity on Pacific nodule fields
}

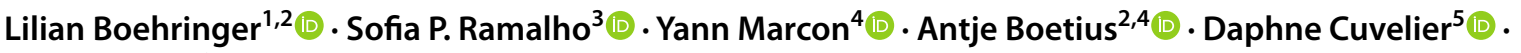 \\ Autun Purser ${ }^{2}$ (1)
}

Received: 23 July 2021 / Revised: 8 October 2021 / Accepted: 19 October 2021 / Published online: 6 December 2021

(c) The Author(s) 2021

\begin{abstract}
Since the late 1980s, various experiments have been conducted in polymetallic nodule fields of the Pacific Ocean to assess the potential environmental impacts of future mining, specifically in two areas: the Peru Basin and the Clarion-Clipperton Fracture Zone (CCZ). Two expeditions, SO242/2 in 2015 (Peru Basin) and SO268/1 + 2 in 2019 (CCZ), deployed a towed camera system to collect imagery from both areas. These expeditions aimed to assess recovery of fauna in the short (few weeks) and long term (several years) following physical seafloor disturbance actions designed to mimic potential mining, by ploughs, dredges and epibenthic sleds. Within the collected image data, several strikingly hexagonal hole patterns were observed and identified as Paleodictyon nodosum, and an irregular form of Paleodictyon traces, both on undisturbed and disturbed areas of seafloor. Recent forms occur abundantly in various deep-sea regions, but their origin, and how they represent the mode of life of the forming organism, remains unknown. In this study, the imaged occurrences of Paleodictyon traces on disturbed seafloor sheds light on the lifecycle of the forming organism, demonstrating that they can recolonize disturbed habitat and produce the trace network in a few weeks. Nevertheless, the density of these patterns on disturbed substrates was lower than observed on undisturbed substrates in both nodule regions. We therefore hypothesize that, along with other benthic deep-sea fauna, these structures and the forming organism are impacted by physical seafloor disturbance, and even 26 years after disturbance, densities on disturbed sediments have not recovered to undisturbed levels.
\end{abstract}

Keywords Clarion-Clipperton Fracture Zone - DISCOL Experimental Area · Deep-sea benthos · Deep-sea mining · Lebensspuren · Graphoglyptids

Communicated by S. Kaiser

This article is a contribution to the Topical Collection Biodiversity in Abyssal Polymetallic Nodule Areas

Lilian Boehringer

lilian.boehringer@awi.de

1 BreMarE Bremen Marine Ecology Center for Research and Education, University of Bremen, Bremen, Germany

2 Alfred Wegener Helmholtz Centre for Polar and Marine Research, Bremerhaven, Germany

3 CESAM - Centre for Environmental and Marine Studies, Department of Biology, University of Aveiro, Campus Universitário de Santiago, Aveiro, Portugal

4 MARUM Center for Marine Environmental Sciences, University of Bremen, Bremen, Germany

5 Institute of Marine Sciences OKEANOS /IMAR, Universidade Dos Açores, Rua Prof. Frederico Machado 4, Horta, Portugal

\section{Introduction}

\section{Polymetallic nodule extraction and disturbance experiments in the Pacific}

On abyssal plains of the Atlantic, Pacific and Indian Ocean polymetallic nodules occur naturally as $5-15 \mathrm{~cm}$ diameter lumps of aggregated minerals. They form at the sea/sediment interface under complex biogeochemical conditions in areas characterized by oligotrophic conditions and low sedimentation rates (Hein and Koschinsky 2013; Kuhn et al. 2017). Extensive nodule fields located in the Pacific tectonic spreading province feature the Clarion-Clipperton Fracture Zone (CCZ) north of the equator and the Peru Basin nodule province south of the equator, which are two of the more intensely studied fields investigated to date (Hein and Koschinsky 2013; Gollner et al. 2017). Polymetallic nodules in the Peru Basin are characterized by higher growth 
rates and larger nodule sizes than those found in the $\mathrm{CCZ}$ (Marchig et al. 2001).

For sessile fauna, these nodules provide hard substrate surfaces on the otherwise predominantly soft and muddy abyssal seafloor plains, and additionally, they influence the distribution of local infauna and bacterial communities (Vanreusel et al. 2016; De Smet et al. 2017; Molari et al. 2020). Further, polymetallic nodules influence local biochemical processes such as particulate accumulation rates and oxygen exchange between seawater and porewater (Haffert et al. 2020; Vonnahme et al. 2020). Seafloor communities in nodule areas have been found to be influenced by surface productivity and deposition of organic matter (Washburn et al. 2021), with nodule size also facilitating the establishment of differing communities (Kuhn et al. 2020).

Because polymetallic nodules contain commercially attractive concentrations of metals (Hein et al. 2013), their collection has been under consideration for exploitation since the 1960s (Auburn 1970). This interest in the potential future economic extraction of these nodules has driven research efforts to try and determine how much of an impact such extraction may have on existing seafloor ecosystems (e.g. Thiel and Schriever 1990; Radziejewska 2002; Gollner et al. 2017; Vonnahme et al. 2020). Areas in the Peru Basin and the CCZ have been subject to various disturbance experiments aimed at elucidating this over the last $4 \mathrm{dec}-$ ades, with nodule removal expected to be a key cause of impacts on biodiversity and ecosystem function resulting from deep-sea mining (Jones et al. 2017). In the Peru Basin as well as in the CCZ, a range of devices, including ploughs and trawls, have been dragged repeatedly across region of nodule abundant seafloor, burying nodules in the sediments or pushing them to the sides of the disturbance tracks. In the Peru Basin nodule province, one of the most exhaustive studied disturbance experiments was conducted in 1989: The DISturbance and ReCOLonization (DISCOL) experiment. Twenty-six years later, in 2015, additional disturbance tracks were induced, and the recolonization of seafloor associated fauna was monitored during the SO242/2 expedition (Boetius 2015). In the CCZ, the seafloor was physically disturbed in 2015 and again in 2019. During the expedition in 2019 (SO268/1+2), the impact of both disturbance events was also monitored using an advanced towed camera system (Linke and Haeckel 2019).

\section{Previous records of Paleodictyon}

The living fossil Paleodictyon Meneghini, 1850 has been interpreted as graphoglyptid trace fossils with horizontal tunnels arranged in a strikingly hexagonal network (Ekdale 1980). They have been found as casts on ancient turbidites, first appearing in the geological record within the early Cambrian (Uchman 2003) in shallow water settings, but moving towards deeper water thereafter, a habitat within which they have become widespread ever since (Uchman 2004; Malekzadeh and Wetzel 2020). Graphoglyptids associated with Paleodictyon are commonly found in flysch sediments distributed all over the world (Kern 1978; Kushlin 1982). Modern patterns of Paleodictyon spp. are still being found on deep-sea sediments (Rona and Merrill 1978; Ekdale 1980). The most recognizable form, Paleodictyon nodosum, is characterized by rows of holes that intersect at an angle of $120^{\circ}$, responsible for the characteristic hexagonal pattern on the sediment surface. The holes are outlets that mark every side of the underlying tube-like structures that penetrate 2-3 mm into the sediment, at which depth they interconnect with a horizontal hexagonal honeycomb network (Rona et al. 2009), reminiscent of the structure of the fossils on turbidites. A second Paleodictyon species, P. tripatens, also frequently observed, exhibits a less regular surface pattern. The vertical outlets are located at three of the six sides of the horizontal hexagonal network in the sediment, thereby producing an irregular surface pattern (Seilacher 2007).

The distribution of the modern forms, specifically $P$. nodosum, appears to be global, with individuals found in the Atlantic, along the Mid-Atlantic Ridge (MAR) (Rona and Merrill 1978; Rona et al. 2009) and the South Atlantic (Ekdale 1980), in the Pacific, along the Australian margin (Przeslawski et al. 2012), in the western (Gaillard 1991), and equatorial regions (CCZ) (Durden et al. 2017 and literature therein) and in the Japan Trench (Swinbanks 1982).

The origin of the living fossil pattern traces has been widely discussed, with two main theories put forward as to what they represent: (1) Paleodictyon forms are trace fossils and the hexagonal network a burrow structure (Garlick and Miller 1993; Wetzel 2000), or traces of microbial 'farms' (Seilacher 2007); alternatively (2) Paleodictyon forms are actually body forms of an organism such as a xenophyophore (Swinbanks 1982; Levin 1994; Rona et al. 2009) or of a compressed hexactinellid sponge (Rona and Merrill 1978; Ehrlich 2019). How the hexagonal network is formed also remains uncertain. Studies have suggested that the pattern typical for $P$. nodosum is a result of growth, rather than burrowing (Plotnick 2003) with the trace developing in a spiral succession from the inner hexagonal ring outwards (Seilacher 2007), in parallel with an increasing trace diameter, with the number of rows of holes and the spacing between the rows also increasing with trace size (Rona et al. 2009). Recent studies indicate that an unknown agglutination agent is used to bind the sediment in the tubes, and a shield-like elevation above the seafloor surface is formed to assist water circulation through the tubes, thereby also increasing the flux of organic particles (Rona et al. 2009). Predictions on the age and state of Paleodictyon patterns found on modern sediments are also difficult to make. In the deep sea, extremely low sedimentation rates and low benthic 
flow velocities render sediment resuspension unlikely and increase the longevity of such traces, so that even after the producer has died, the traces may remain visible (Wheatcroft et al. 1989; Connolly et al. 2020). How long such patterns will last depends primarily on the rates at which other epibenthic megafauna may disturb seafloor sediments and trace patterns, overlaying these with their own trail patterns, or on diffusive bioturbation by meio- and macrobenthos, or to a lesser extent on local sediment accumulation rates, which may eventually cover the patterns (Wheatcroft et al. 1989). The patterns were recently observed to occur abundantly in close vicinity of manganese nodules (Durden et al. 2017), which raised the question of the response of the forming organism to physical disturbances associated with nodule removal.

Here we analyzed seafloor images collected during two expeditions to polymetallic nodule provinces in the $\mathrm{CCZ}$ and DEA (SO242/2 and SO268/1+2). During each of these expeditions, areas of undisturbed and physically disturbed seafloor were imaged. Paleodictyon traces on the seafloor after recent dredge (monitored after 17-18 days in the CCZ), EBS trawls (monitored after 6 weeks in the DEA and after 4 years in the $\mathrm{CCZ}$ ) and ploughed tracks (monitored after 26 years in the DEA) disturbances were quantified, allowing the first assessment of the recovery potential of Paleodictyon traces after physical disturbance in abyssal sediments to be made.

\section{Materials and methods}

\section{Disturbance experiments}

The DISCOL experiment was conducted in the Peru Basin nodule province in 1989. In an area of $10.8 \mathrm{~km}^{2}$, an 8 -m-wide plough-harrow was used to overturn the seafloor across 78 towed dredges, resurfacing approximately $20 \%$ of the DISCOL experimental area (DEA) (Thiel and Schriever 1990). These dredges produced 10-15-cm-deep seafloor scars and removed nodules from the surface by ploughing them into the seafloor-overturning and disturbing the seafloor sediments themselves. In 2015, a two leg expedition (SO242/1 and SO242/2) revisited the DEA 26 years after disturbance (Boetius 2015; Greinert 2015). During the first expedition leg (SO242/1), additional disturbance was induced with an epibenthic sledge (EBS), towed several times across the seafloor, leaving a scar of $\sim 30 \mathrm{~cm}$ depth and removing all overlying sediments. Six weeks later, the second expedition leg (SO242/2) used an advanced towed camera system, the Ocean Floor Observation System (OFOS), to survey the disturbed seafloor. The higher quality cameras mounted on the SO242/2 OFOS were far superior to those mounted for the initial 1989 and 1990s surveys of the region, and smaller seafloor features (fauna, animal traces, microtopography) could be clearly distinguished in collected images. This modern towed system therefore allowed seafloor features and fauna of sizes $>1 \mathrm{~cm}$ in diameter to be quantified across disturbed and undisturbed areas of seafloor.

In the $\mathrm{CCZ}$, the $\mathrm{SO} 239$ expedition induced disturbance tracks in 2015 by towing an EBS four times across the seafloor (Martínez Arbizu and Haeckel 2015). Four years later, in 2019, the SO268/1+2 expedition monitored the impact of this disturbance by conducting towed camera transects with the OFOS. During this expedition, an additional small-scale disturbance experiment was carried out, with a 1.5 -m-wide chain dredge being towed 11 times over an area covering $100 \times 500 \mathrm{~m}$, leaving dredge tracks of $\sim 5 \mathrm{~cm}$ depth. This site was revisited 17-18 days after disturbance, and the disturbance impact again monitored using the OFOS (Linke and Haeckel 2019).

\section{Image data collection}

The OFOS was used to survey the DEA during SO242/2 in October 2015 and the eastern BGR (Bundesanstalt für Geowissenschaften und Rohstoffe) exploration area in the CCZ during SO268/1 + 2 in May 2019 (Fig. 1). The OFOS consisted of a 24-megapixel camera, an HD video camera, multiple lights, three lasers, an altimeter (Tritech) and a USBL POSIDONIA positioning beacon. The construction was similar to the OFOBS described in Purser et al. (2019), the only difference being the absence of the inertial navigation system, side scan and forward-facing sonar systems on the OFOS system.

For the current study, the OFOS was towed across the CCZ seafloor during three transects and across the DEA seafloor for eight transects, conducted at an altitude of $\sim 1.5$ to $1.7 \mathrm{~m}$ and ship speed of $0.2-0.54 \mathrm{kn}$, collecting still images and video data from three categories of seafloor sediments: (1) 'undisturbed' nodule abundant seafloor, (2) 'recently disturbed' seafloor (17-18 days (CCZ) and 6 weeks (DEA) after the physical disturbance) with evident traces and (3) 'historically disturbed' seafloor (4 (CCZ) and 26 (DEA) years after the physical disturbance) (Fig. 2). Timed images were collected every 10 (CCZ) and 15 (DEA) seconds, covering approximately $5 \mathrm{~m}^{2}$ of seafloor per image.

\section{Image analysis}

Images originated from the transects in the BGR exploration area (CCZ, depth range 4118-4120 m) and the transects in the DEA (depth range 4090-4189 m) were then used for image analysis and annotation of Paleodictyon traces (Table 1). Images from both data sets in some way unsuitable for analysis (such as completely black images taken during the deployment or retrieval of the device, as well 


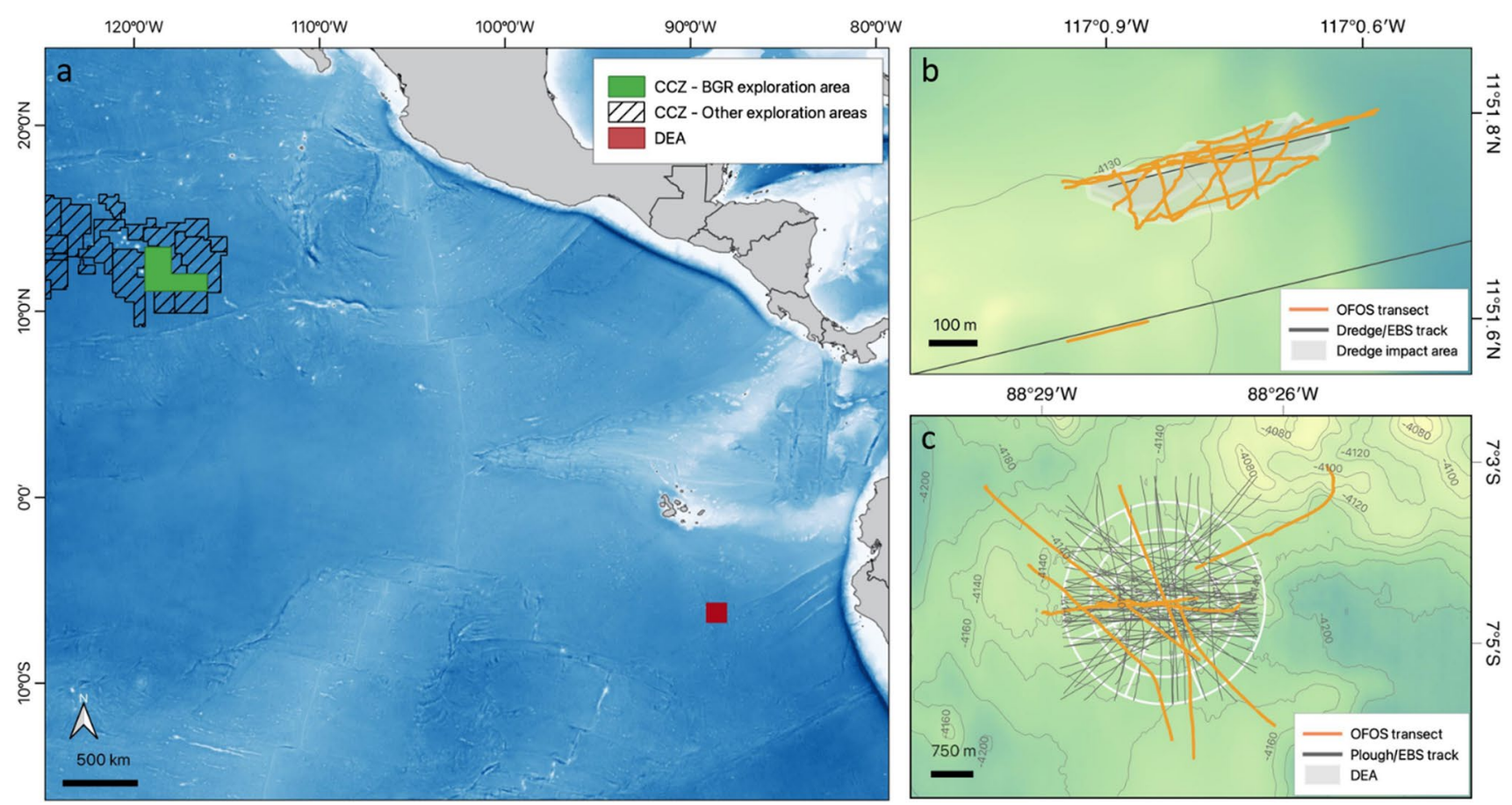

Fig. 1 Overview of study areas. a Map of the eastern equatorial Pacific Ocean where the Clarion-Clipperton Fracture Zone (CCZ) and the DISCOL Experimental Area (DEA) are located; b Ocean
Floor Observation System (OFOS) transects in the BGR (Bundesanstalt für Geowissenschaften und Rohstoffe) license area within the CCZ; c OFOS transects in the DEA. (Map source: GEBCO)
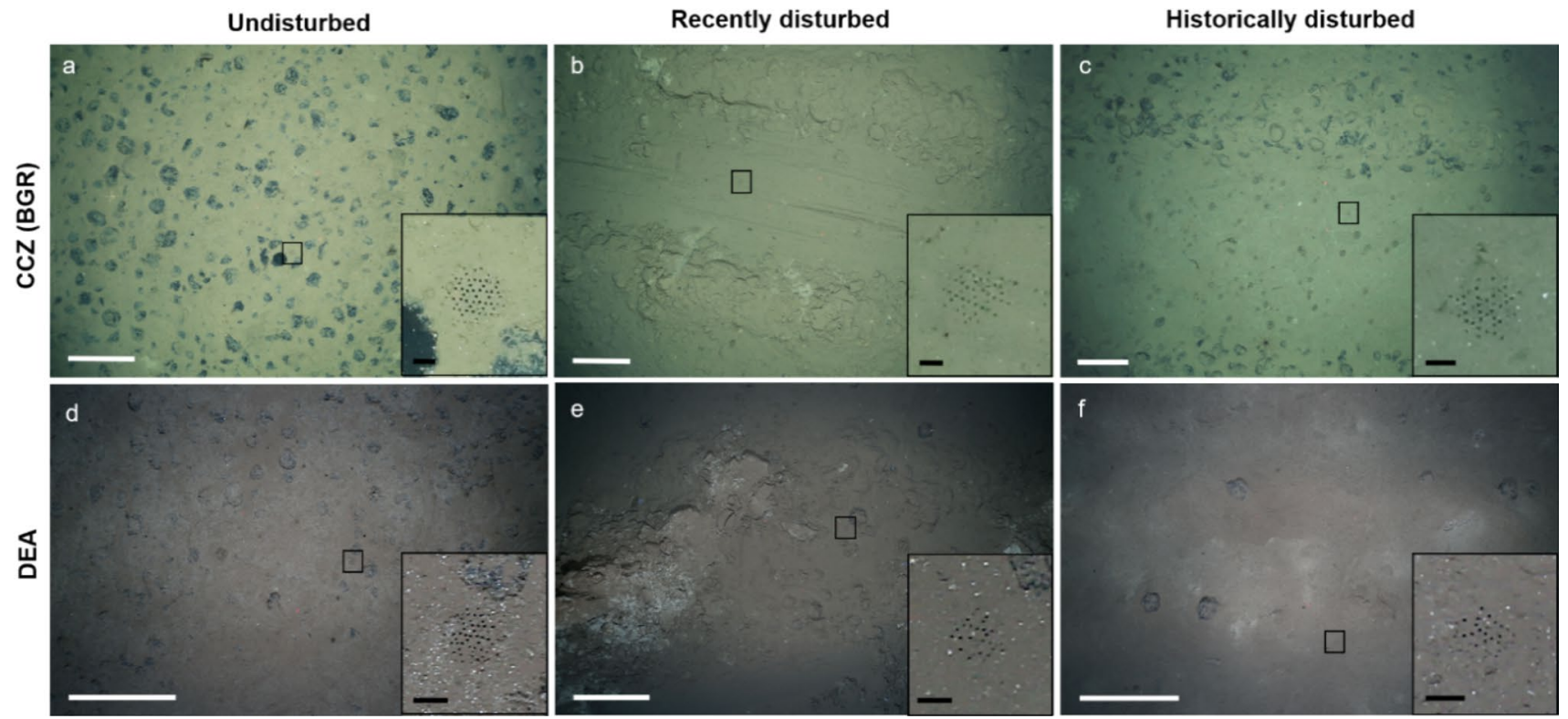

Fig. 2 Substrate categories in both experimental areas with Paleodictyon patterns. Clarion-Clipperton Fracture Zone (CCZ): a-c with a undisturbed; $\mathbf{b}$ recently disturbed (17-18 days) using a chain dredge; c historically disturbed (4 years) using an Epi-Benthic Sledge. DISCOL Experimental Area (DEA): $\mathbf{d}-\mathbf{f}$ with $\mathbf{d}$ undisturbed; e recently disturbed (6 weeks) using an Epi-Benthic Sledge; $\mathbf{f}$ historically disturbed (26 years) using a plough-harrow. Black rectangle indicates the location of Paleodictyon pattern. White bars indicate $50 \mathrm{~cm}$. Black bars indicate $2 \mathrm{~cm}$ 
Table 1 Number of images taken and analyzed, total annotated area $\left(\mathrm{m}^{2}\right)$ covered during transects in the Clarion-Clipperton Fracture Zone (CCZ) and the DISCOL Experimental Area (DEA) with indica- tion of time after disturbance. Numbers in bold represent the combined totals for image numbers and areas surveyed across the $\mathrm{CCZ}$ and DEA provinces, respectively

\begin{tabular}{|c|c|c|c|c|c|c|c|c|c|}
\hline & Transect & $\begin{array}{l}\mathrm{N}^{\circ} \text { in undisturbed } \\
\text { area analyzed/ } \\
\text { available }\end{array}$ & $\begin{array}{l}\text { Analyzed } \\
\text { area }\left(\mathrm{m}^{2}\right)\end{array}$ & $\begin{array}{l}\mathrm{N}^{\circ} \text { in recently } \\
\text { disturbed area } \\
\text { analyzed/avail- } \\
\text { able }\end{array}$ & $\begin{array}{l}\text { Analyzed } \\
\text { area }\left(\mathrm{m}^{2}\right)\end{array}$ & $\begin{array}{l}\text { Time after } \\
\text { distur- } \\
\text { bance }\end{array}$ & $\begin{array}{l}\mathrm{N}^{\circ} \text { in historically } \\
\text { disturbed area } \\
\text { analyzed/avail- } \\
\text { able }\end{array}$ & $\begin{array}{l}\text { Analyzed } \\
\text { area }\left(\mathrm{m}^{2}\right)\end{array}$ & $\begin{array}{l}\text { Time after } \\
\text { disturbance }\end{array}$ \\
\hline \multirow[t]{4}{*}{ CCZ (SO268) } & OFOS05 & $337 / 337$ & 4938 & $0 / 0$ & NA & 0 & $27 / 27$ & 115 & 4 years \\
\hline & OFOS11 & $189 / 1919$ & 1446 & $159 / 159$ & 802 & 17 days & NA & NA & \\
\hline & OFOS12 & $444 / 444$ & 2478 & $112 / 112$ & 658 & 18 days & $89 / 89$ & 656 & 4 years \\
\hline & & $970 / 2700$ & 8862 & $271 / 271$ & 1460 & & $116 / 116$ & 773 & \\
\hline \multirow[t]{9}{*}{ DEA (SO242) } & $143-1$ & $557 / 557$ & 2785 & $0 / 0$ & NA & & $107 / 107$ & 535 & 26 years \\
\hline & $155-1$ & $382 / 382$ & 1910 & $0 / 0$ & NA & & $416 / 416$ & 2080 & 26 years \\
\hline & $160-1$ & $96 / 96$ & 480 & $0 / 0$ & NA & & $6 / 6$ & 30 & 26 years \\
\hline & $164-1$ & $889 / 889$ & 4445 & $0 / 0$ & NA & & $15 / 15$ & 75 & 26 years \\
\hline & $171-1$ & $548 / 548$ & 2740 & $0 / 0$ & NA & & $365 / 365$ & 1825 & 26 years \\
\hline & $174-1$ & $671 / 671$ & 3355 & $0 / 0$ & NA & & $110 / 110$ & 550 & 26 years \\
\hline & $197-1$ & $643 / 643$ & 3215 & $137 / 137$ & 685 & 6 weeks & $123 / 123$ & 615 & 26 years \\
\hline & $203-1$ & $784 / 784$ & 3920 & $0 / 0$ & NA & & $136 / 136$ & 680 & 26 years \\
\hline & & $4570 / 4570$ & 22,850 & 137/137 & 685 & & $1415 / 1415$ & 6390 & \\
\hline
\end{tabular}

as images taken at an altitude of more than $3 \mathrm{~m}$ or with suspended sediments obscuring seafloor visibility) were excluded from the analysis.

The image annotations were done using the program BIIGLE (Langenkämper et al. 2017) for images from the CCZ and PAPARA(ZZ)I (Marcon and Purser 2017) for images from the DEA. Occurrences of the typical hexagonal small hole arrays distinctive of $P$. nodosum surface traces were annotated as 'Paleodictyon nodosum'. Unfinished or irregular hole arrays, possibly including P. tripatens, were annotated as 'Irregular Paleodictyon' (Fig. 2). The diameter of each hole array was additionally measured. All patterns were annotated based on downward-facing visual observations. No additional measurements for clarification of the taxonomy, e.g. sediment penetration or determination of a shield-shaped elevation of the sediment layer, were possible. Hence, patterns annotated as 'Irregular Paleodictyon' could not be identified further.

In addition to identifying Paleodictyon traces, the substrate on which the observation was made was also labelled according to the substrate categories mentioned above ('undisturbed', 'recently disturbed' and 'historically disturbed', Fig. 2). Patterns observed on disturbed substrate were those present within actual disturbance tracks, indicated by removed or overturned surface sediments. The 'undisturbed' substrate category refers to substrate inside the disturbed areas but without visible disturbance tracks. No additional transects in reference areas were conducted. Therefore, despite the undisturbed substrate not being actively physically disturbed, there is the potential that images classified as 'undisturbed' could actually be subjected to enhanced sedimentation as a result of the suspended sediment plume created during the physical disturbance.

The total area annotated was $10,437 \mathrm{~m}^{2}$ for $\mathrm{CCZ}$ and 29,925 $\mathrm{m}^{2}$ for DEA. The area of each seafloor category annotated during each transect is given in Table 1. Density of Paleodictyon traces was expressed in number of patterns per square meter $\left(\mathrm{m}^{-2}\right)$.

\section{Statistical analysis}

The statistical analysis was done using the statistical computing software $\mathrm{R}$ (Version 3.4.3). The different transects were treated as replicates and the seafloor substrate categories as factors. Beforehand, the data were tested for homogeneous variances with the Levene's test and normality using the Shapiro-Wilk test. Additional data distribution and residual plots were produced. For comparison of the densities between all three substrate categories of both P. nodosum and irregular Paleodictyon patterns, a non-parametric Kruskal-Wallis Rank Sum Test following a multiple comparison test after Kruskal-Wallis was performed.

To analyze the similarity between transects within CCZ and DEA and taking into account quantitative and qualitative variables a factor analysis of mixed data was additionally performed, the quantitative variable being the density of Paleodictyon traces and the qualitative variables being the disturbance (disturbed/ undisturbed) and the time since disturbance (recent/historical). 


\section{Results}

Hexagonal patterns associated with Paleodictyon nodosum and irregular Paleodictyon patterns were found on all substrate categories in both, $\mathrm{CCZ}$ and the DEA area, with the overall average being 53 times higher in the $\mathrm{CCZ}$ (CCZ: $0.1218 \pm 0.1269$ patterns $\mathrm{m}^{-2}$; DEA: $0.0023 \pm 0.0028$ patterns $\mathrm{m}^{-2}$ ).

Across both areas, the densities of Paleodictyon patterns varied with substrate category (Fig. 3), with highest densities consistently found on undisturbed substrate at the CCZ and the DEA $(0.2083 \pm 0.1442$ and $0.0033 \pm 0.0019$ patterns $\mathrm{m}^{-2}$ ).

For the $\mathrm{CCZ}$, the second highest densities were observed on the 4-year-old tracks (historically disturbed) for both Paleodictyon categories, followed by the lowest densities being observed on the recently disturbed tracks (Fig. 3). Average densities of $P$. nodosum observed on the recent dredge tracks (18 days post-disturbance) were 13 times lower than those observed on undisturbed substrate $(0.0122 \pm 0.0060$ vs. $0.1547 \pm 0.0800$ patterns $\mathrm{m}^{-2}$, respectively), though if these trace numbers were combined with the counts for irregular patterns, this was reduced to a six times lower abundance $(0.0356 \pm 0.0262$ vs. $0.2083 \pm 0.1442$ patterns $\mathrm{m}^{-2}$ ). After 4 years (EBS), densities for $P$. nodosum were still five times lower than observed on undisturbed seafloor $(0.0337 \pm 0.0075$ vs. $0.1547 \pm 0.0800$ patterns $\mathrm{m}^{-2}$ ), though three times higher compared to recently disturbed sediments $(0.0337 \pm 0.0075$ vs. $0.0122 \pm 0.0060$ patterns $\mathrm{m}^{-2}$ ). For the irregular patterns, densities on 4 years post-disturbance seafloor were half the density observed on undisturbed substrate $(0.1228 \pm 0.0618$ vs. $0.2619 \pm 0.1716$ patterns $\mathrm{m}^{-2}$ ), though twice as high as densities on areas of seafloor exposed to recent disturbance $(0.1228 \pm 0.0618$ vs. $0.0590 \pm 0.0154$ patterns $\mathrm{m}^{-2}$ ). However, results of the Kruskal-Wallis Rank Sum Test showed no significant difference between densities of both Paleodictyon categories ( $P$. nodosum and irregular patterns) on the different substrate types (Kruskal-Wallis chi-squared $=9.4, \mathrm{df}=5$, $p$-value $=0.09413$ ) .

In the DEA, only irregular Paleodictyon patterns were found on recently disturbed substrate (6 weeks post EBS), but this density was similar to the densities found on undisturbed substrate for total combined Paleodictyon patterns. However, densities on historically disturbed substrate (26 years post plough) were overall the lowest (Fig. 3). For $P$. nodosum on historically disturbed substrate, the densities were significantly lower (eight times) than densities observed on undisturbed substrate $(0.0005 \pm 0.0010$ vs. $0.0039 \pm 0.0020$ patterns $\mathrm{m}^{-2}$ ) (multiple comparison test after Kruskal-Wallis, $p$-value 0.05 , historically disturbed-undisturbed, observed difference $=15.6875$, critical difference $=13.1662$ ). For irregular Paleodictyon patterns, this difference was not significant, albeit the average density was seven times lower than on undisturbed substrate, when an outlier measurement was excluded $(0.0004 \pm 0.0005$ vs. $0.0027 \pm 0.0015$ patterns $\mathrm{m}^{-2}$ ). Comparison of density on recently disturbed substrate and historically disturbed substrate showed a seven times higher abundance of irregular Paleodictyon patterns on the historically disturbed substrate when excluding the outlier on historically disturbed substrate $\left(0.0029 \pm 0\right.$ vs. $0.0004 \pm 0.0005$ patterns $\left.\mathrm{m}^{-2}\right)$.

The similarity of transects in densities of P. nodosum and irregular patterns in the light of the disturbance (disturbed/undisturbed) and the time since disturbance

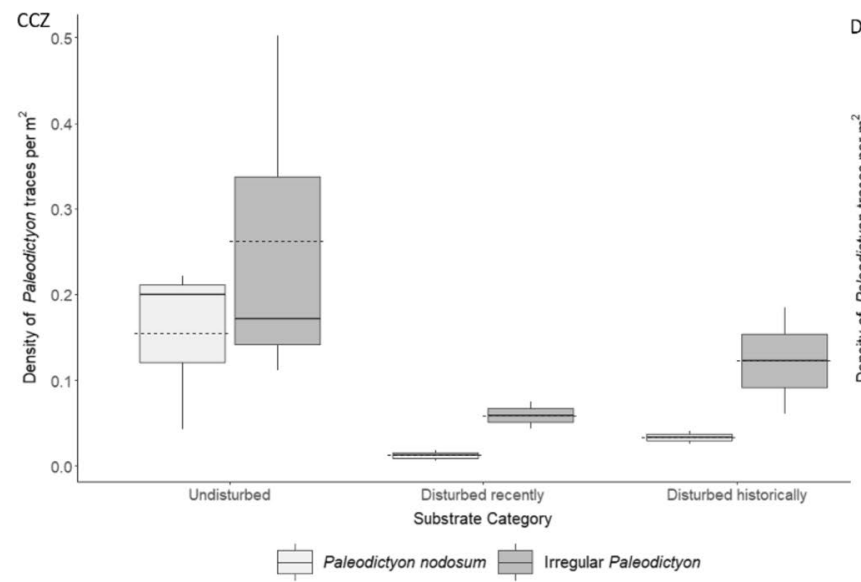

Fig. 3 Density of Paleodictyon traces (patterns $\mathrm{m}^{-2}$ ) on three different substrate categories in the Clarion-Clipperton Fracture Zone (CCZ) (left) and in the DISCOL Experimental Area (DEA) (right). The horizontal line in the DEA for recently disturbed substrate rep-

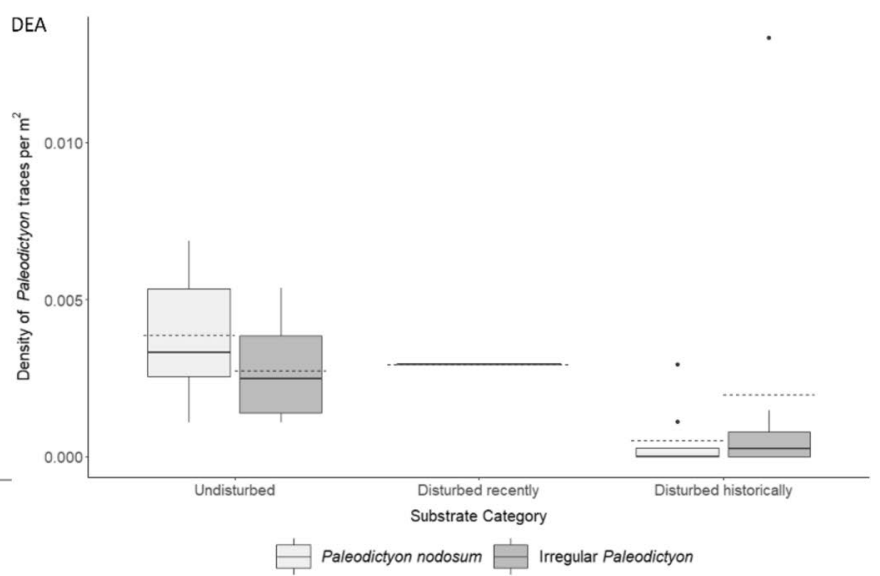

resents irregular Paleodictyon patterns. Boxes indicate 25th to 75th percentiles. Solid horizontal lines indicate median, dashed horizontal lines indicate mean, whiskers the full range and circles outliers 
(Recent / Historical) is shown in the factor analysis of mixed data for the CCZ and the DEA (Fig. 4). The variable time since disturbance also includes the patterns observed on undisturbed substrate, because those were still within the general area that was physically disturbed, although not being directly on the disturbance tracks. In the left panels, the vertical separation coincides with a split between the patterns on the undisturbed substrate and on disturbed tracks both for CCZ and DEA. A horizontal separation can be observed in the right panels based on the time since disturbance, where the more recent disturbance features generally lower densities than the historical data.

Paleodictyon patterns were larger in size (diameter) at $\mathrm{CCZ}$ when compared with patterns observed in the DEA, i.e. on average $4.7 \pm 1.5 \mathrm{~cm}$ for $P$. nodosum patterns on undisturbed substrate within the $\mathrm{CCZ}$, compared to $3.0 \pm 0.7 \mathrm{~cm}$ within the DEA. However, average size did not vary significantly with substrate category, across either of the experimental area.
Fig. 4 Similarity of transects based on two dimensions for disturbance: disturbed (D) and undisturbed (U) and time since disturbance: recently (Rec, 17-18 days in the Clarion-Clipperton Fracture Zone (CCZ) and 6 weeks in the DISCOL Experimental Area (DEA)) and historical (Hist, 4 years in the $\mathrm{CCZ}$ and 26 years in the DEA) analyzed with the factor analysis of mixed data for the $\mathrm{CCZ}$ (above) and DEA (below)
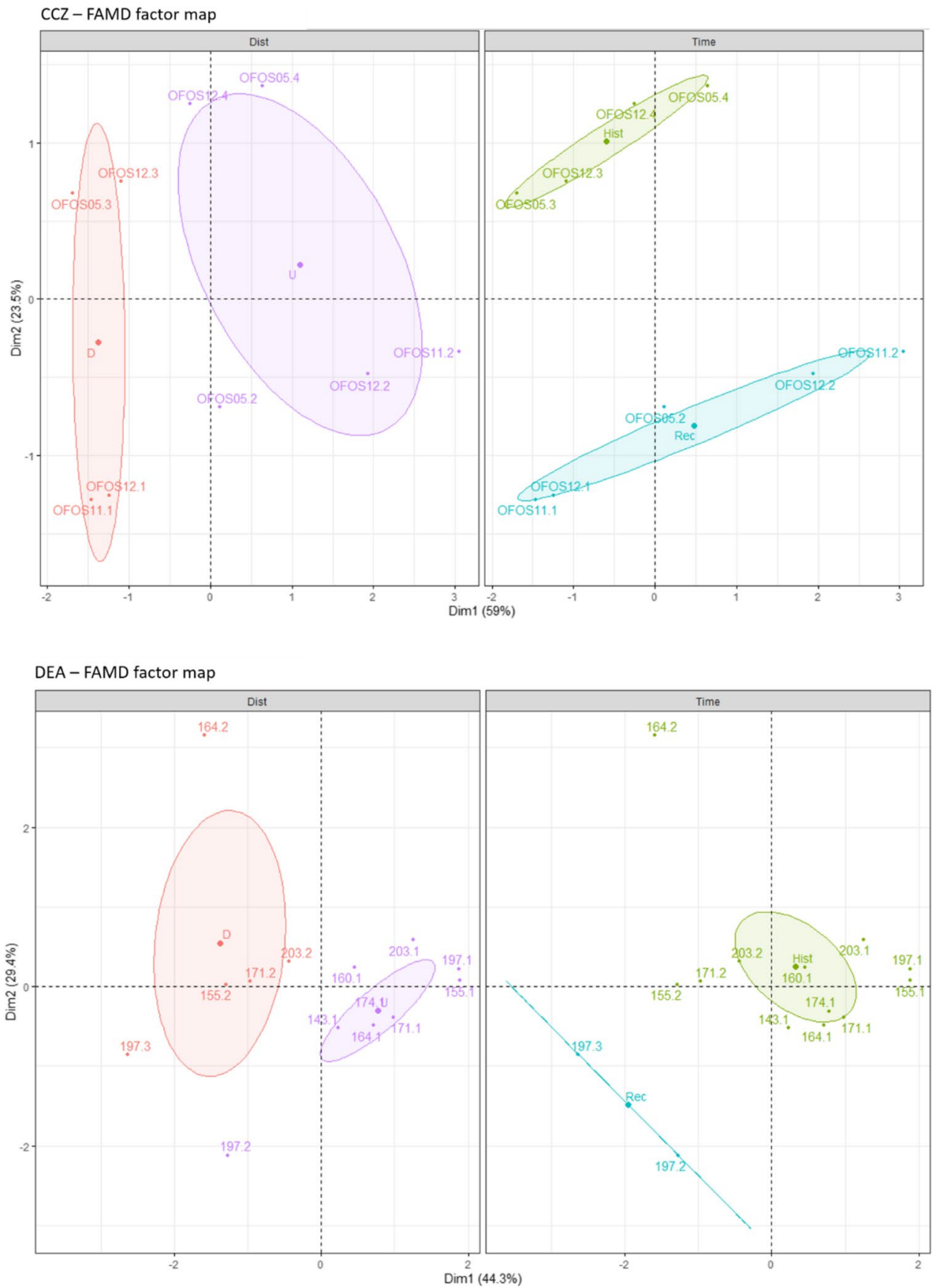
Additionally, Paleodictyon patterns were found around and partially on top of nodules covered with thin sediment layers in the CCZ (Fig. 5).

\section{Discussion}

In this study, two different forms of Paleodictyon patterns were observed on the deep-sea sediments, matching the previous analysis of Durden et al. (2017). The strikingly hexagonal hole structure of $P$. nodosum and a less regular version of the structure referred to in this study as exhibiting an irregular Paleodictyon pattern. The latter may also be a modification of the typical pattern of $P$. nodosum produced in response to an uneven substrate or material within the sediment. This less rigid trace may also have been generated by the related and less regular form $P$. tripatens (Seilacher 2007).

\section{Disturbance and recovery of Paleodictyon patterns}

Paleodictyon nodosum and irregular Paleodictyon patterns were found on substrate which had been disturbed only
17-18 days (CCZ) and 6 weeks (DEA) prior to visual survey. These disturbance experiments caused the removal and reworking of the surface sediment layers to differing degrees and removed fauna and associated traces, reaching depths of few $\mathrm{cm}$ in the $\mathrm{CCZ}$ and down to at least $15 \mathrm{~cm}$ in the DEA (Thiel 2001; Vonnahme et al. 2020). The fragile and highly regular hexagonal tube structure of $P$. nodosum only reaches about 2-3 $\mathrm{mm}$ into the sediment with the patterns slightly elevated (ca. $0.5 \mathrm{~cm}$; Rona et al. 2009). This leads to the conclusion that the traces were completely removed by the physical disturbance and that the producing organism has a fast recolonization ability following the disturbance event.

Despite the re-appearance of Paleodictyon patterns on disturbed substrate, the mean densities for $P$. nodosum and irregular Paleodictyon were lower in these areas than those observed on undisturbed substrate in both areas, and even densities on substrates disturbed 26 years prior to visual survey in the DEA had not recovered to pre-impact levels. However, in the CCZ, densities of both Paleodictyon pattern categories were higher on historically disturbed substrate when compared to recently disturbed substrate. Even so, as observed within the DEA, densities in the CCZ had not returned to pre-disturbance densities after 4 years, indicating
Fig. 5 Observations of Paleodictyon patterns around and partially overlaying the upper flanks of nodules covered with thin sediment layers in the Clarion-Clipperton Fracture Zone (CCZ). Black bars indicate $3 \mathrm{~cm}$

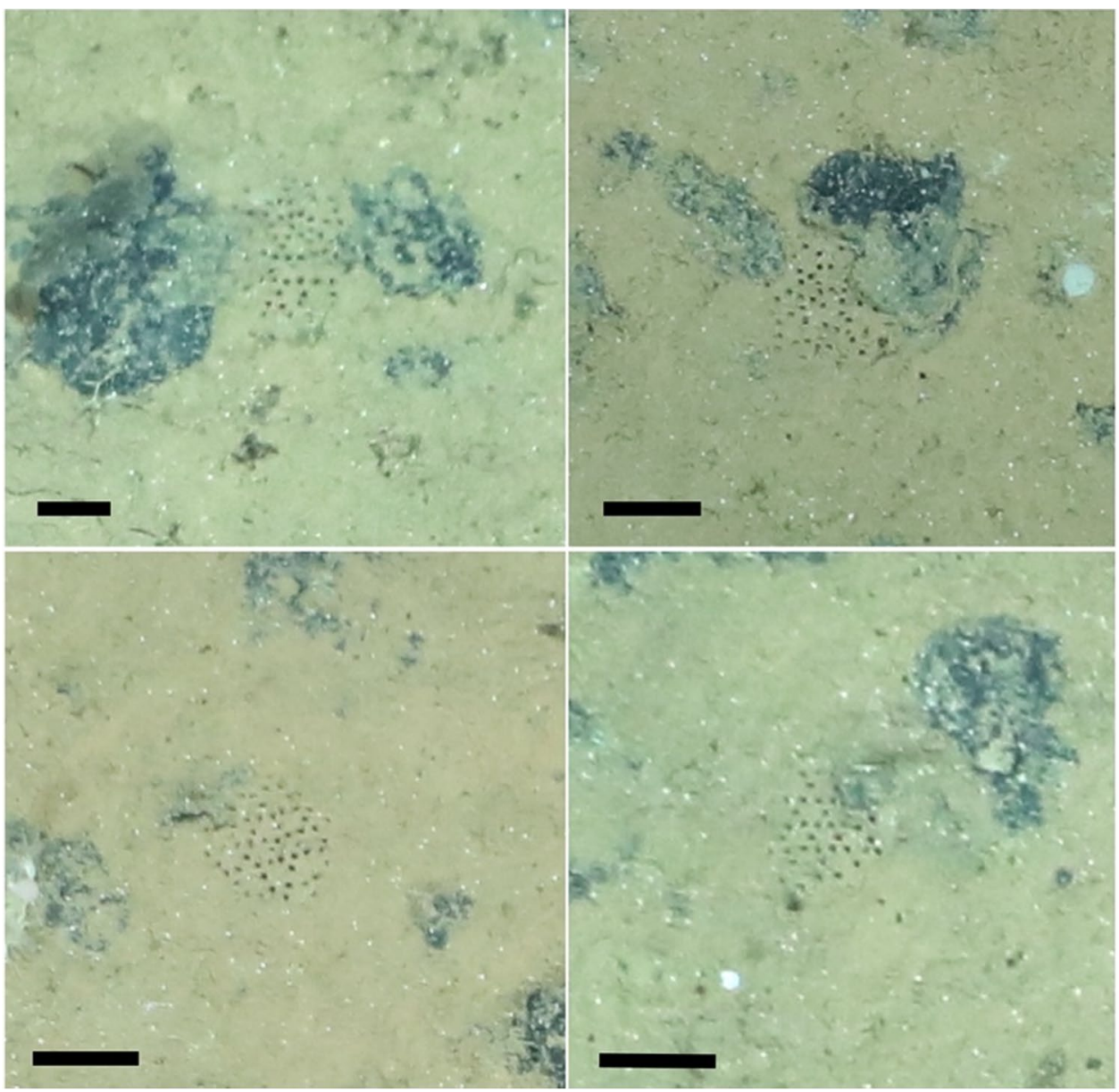


that re-establishment progresses slowly. In the DEA, the densities on recently disturbed substrate were similar to those on undisturbed substrate in the analyzed data set. However, it should be noted that the transect covering recently disturbed substrate comprised an area almost 10 times smaller (685 $\mathrm{m}^{2}$ ) than the total historically disturbed substrate area $(6390$ $\mathrm{m}^{2}$ ) surveyed in this study. Therefore, the high density of Paleodictyon patterns in recently disturbed areas in the DEA may be a very local phenomenon.

Generally, processes in the deep sea are slower than elsewhere, given the low nutrient fluxes common in these ecosystems, and disturbed and displaced fauna may need a long time to recover and recolonize a region (Grassle 1977; Thiel 2001). In the DEA, other benthic fauna showed similarly slow recovery rates, and the negative impact on density and diversity produced by the plough-harrow was still evident in the decade after the disturbance (Bluhm 2001). Recovery rates were observed to be particularly low for sessile and less mobile megafauna, e.g. actiniarians and asteroids, which were only again observed in seafloor surveys conducted at least 7 years after disturbance, whereas more mobile taxa such as ophiuroids, sea cucumbers, fish and hermit crabs were frequently observed on the disturbance tracks in the first few years after disturbance (Bluhm 2001). Faunal community conditions resembling those present before the experimental disturbances were not returned to even 26 years after (Jones et al. 2017; Simon-Lledó et al. 2019). In the CCZ, mega-epifauna did not fully recover even after 37 years (Vanreusel et al. 2016). As observed within the DEA, different taxa responded differently to the disturbance impacts in the CCZ. The sessile epifauna, being diverse, was represented in the area primarily by sponges, actiniarians, alcyonacean and antipatharian corals in the undisturbed reference area, whereas in the disturbance tracks, the bulk of these fauna was represented primarily by actiniarians (Vanreusel et al. 2016). Meio-infaunal communities had also not recovered after 30 years (Miljutin et al. 2011). For infauna, sediment compaction and extraction of the upper sediment layer are thought to be the main causal factors in delaying faunal density recovery (Gollner et al. 2017).

The degree and type of disturbance generated by the various disturbance experiments might also influence the differences in Paleodictyon pattern recovery or re-establishment rates. As the structure of $P$. nodosum is slightly elevated but reaches only few mm's into the substrate (Rona et al. 2009), it would be completely destroyed by all disturbing devices used in the current study. All physical disturbance devices modify the seafloor in a different way; the dredge used to produce the recent disturbance in the $\mathrm{CCZ}$ disturbed only the upper $\sim 5 \mathrm{~cm}$ of sediment, shallower than the $\sim 30-\mathrm{cm}$ deep disturbance tracks made by the EBS or the plough harrow within the DEA. We thus argue that the relatively high densities of Paleodictyon patterns observed on recently disturbed substrate, only 17-18 days after disturbance, suggest that the patterns are associated with a life form that can either hide in deeper seafloor layers (a few $\mathrm{cm}$ below the surface) or has the ability to quickly reproduce the pattern structure. Previous studies conducted in the DEA also found that the impact of physical disturbance on biogeochemistry, nutrient fluxes and microbial biomass depends on the degree and type of physical disturbance, which therefore is connected to fauna diversity and inevitably their activity in the sediments (Haffert et al. 2020; Vonnahme et al. 2020). The disturbance and recolonization patterns detected here suggest that the Paleodictyon traces are related to a life form that responds to losses in seafloor integrity, with this response more marked in areas of heavy disturbance than in superficially disturbed areas.

In addition to animals directly impacted by the disturbance, adjacent areas of seafloor and fauna present in these areas have been hypothesized to also be affected by disturbance. In the DEA, the suspended sediment clouds produced by the plough-harrow were predicted to have settled in an area of $1-2 \mathrm{~km}$ from the plough itself covering the seafloor with new sediment layers of $>100 \mathrm{~g} \mathrm{~m}^{-2}$ (Jankowski and Zielke 2001), thus possibly covering Paleodictyon patterns in the vicinity of the ploughs or tracks of other seafloor disturbing devices. The maximum density of $P$. nodosum on undisturbed substrate in the DEA was 0.0068 patterns $\mathrm{m}^{-2}$ which is much lower than densities observed elsewhere globally (see numbers below reported by Durden et al. 2017 and Rona and Merrill 1978). In the CCZ, we observed a density of Paleodictyon spp. of $0.22-0.50$ patterns $\mathrm{m}^{-2}$ on undisturbed substrate, which was similar to densities reported by Durden et al. (2017) (0.33 patterns $\mathrm{m}^{-2}$ ) for this area, but still much lower when compared to the densities found at the MAR, where densities ranging from 1-45 patterns $\mathrm{m}^{-2}$ (Rona and Merrill 1978) were observed. If patterns were covered with sediments, which could be as thick as $30 \mathrm{~mm}$ following resuspension or sediment overturn associated with mining (Schriever et al. 1992; Jankowski and Zielke 2001), the overall density of Paleodictyon patterns could have been drastically reduced. Unfortunately, there are no available data on the density of $P$. nodosum in the DEA before the ploughing 26 years ago, with the cameras deployed in the pre-disturbance surveys having insufficient resolution to detect these patterns. However, data from the $\mathrm{CCZ}$ indicate that in this area, reduced densities due to sedimentation were minimal, as Paleodictyon patterns were observed on top of thick sediment cover (unpublished data) and the overall densities were similar to those observed in other parts of the $\mathrm{CCZ}$ not subject to disturbance experiments as mentioned above.

Given the relatively small size of $P$. nodosum patterns, especially the small patterns observed in the DEA (mean diameter $2.96 \mathrm{~cm} \pm 0.71 \mathrm{~cm}$ ), the image resolution and 
the camera itself should be taken into consideration when interpreting and comparing data sets collected here and elsewhere. Using different camera systems influences the success rate of spotting small features tremendously (Schoening et al. 2020).

\section{Formation of patterns}

To date, there are only assumptions on the formation mechanisms behind the production of distinct and typical network structure of Paleodictyon. It is unclear whether the network structure is a result of organism activity or growth itself. While we cannot shed light on the actual formation process of Paleodictyon structures, interesting observations were made during this study, which supports the hypothesis of a trace pattern rather than organismal growth. As Paleodictyon patterns were observed, reformed only 17-18 days after the sediment was disturbed with a chain-dredge, suggesting an ad-hoc formation of the structure. A formation process as a result of the growth of an organism, as suggested by Plotnick (2003), seems unlikely since the observed patterns had already reached a diameter of $3-5 \mathrm{~cm}$, implying a growth rate of $>1 \mathrm{~cm}$ week $^{-1}$. For example, the growth hypothesis of, e.g. xenophyophores being responsible for the formation of these patterns is challenged by the observed time span of just over 2 weeks, which would be too short for the development of such a pattern of a diameter of 3-5 cm. Even though certain species of xenophyophores have been observed to exhibit episodically high growth rates of $1 \mathrm{~cm}^{3}$ volume increase during an interval of 9-33 h, after this growth spurt, further growth did not occur in the subsequent two months (Gooday et al. 1993).

Paleodictyon patterns have commonly been observed on soft substrate around nodules, or with nodules interrupting the pattern directly (Durden et al. 2017). Within the current study however, there are several images, which seem to indicate that the patterns occurred partially on thin sediments draped on top of partially buried nodules (Fig. 5). It could be possible that the holes in the patterns observed on these lightly covered nodules do not extend down to a horizontal network, but rather occur superficially and are not interconnected with the neighbouring holes. This would point towards a formation process starting on the surface as opposed to one developing inside the sediment from the inner hexagonal ring outwards. In contrast, although not statistically assessed in the current study, Paleodictyon traces were often directly abutting nodules, rather than being formed in the sediment abundant regions between nodules. This would seem to support the idea of a formation from below, rather than directly from a sinking benthopelagic source. If such a benthopelagic source was in action, a more randomized distribution might have been expected.
Both scenarios provide new information on the formation of the poorly understood Paleodictyon patterns and structure, and although the mystery as to what aspect of the forming organism lifestyle is represented by the patterns persists, the new findings reported here contribute to the discussion on the origin of Paleodictyon patterns. Future efforts to elucidate this could employ $16 \mathrm{~S}$ rRNA technologies or deploy time-lapse cameras in the vicinity of these patterns, ideally in areas with exceptional high pattern densities.

\section{Conclusion}

The current study emphasizes new aspects of the formation and stability of the poorly known Paleodictyon nodosum hexagonal seafloor trace pattern and the more irregular form also observed across the ocean seafloors of the world. The distinctive hexagonal trace pattern was found on the surface of substrates that had been subjected to different degrees of anthropogenic physical disturbance, both recently and historically, in the CCZ and the DEA. Our observations clearly demonstrate that Paleodictyon can recolonize new substrate and form its distinctive network in a time period of just over 2 weeks to 26 years. However, densities of Paleodictyon patterns on disturbed substrates clearly remain lower decades after disturbance when compared to densities observed on undisturbed adjacent and comparable substrates, even decades after the original disturbance, suggesting that the respective life form is either driven away by the disturbance or even killed. Information on the lifecycles of deep-sea creatures in nodule ecosystems are still under active investigation (see Purser et al. 2016), and the full extent of the impacts which may result from experimental disturbances mimicking deep-sea mining are not yet fully understood. It is crucial that more knowledge about nodule ecosystem functioning is gathered to better understand the reestablishment potential of the fauna inhabiting these regions before the onset of commercial extraction of this resource commences. As shown here, using appropriate camera systems is an applicable approach for gauging benthic organisms' abundances remotely. With further knowledge on fauna lifecycles and biogeochemical processes at work in these areas, imaging data can be used to develop appropriate management and monitoring plans to gauge, minimize and mitigate against any potentially negative ecosystem consequences of future deep-sea mining.

Acknowledgements The crews and scientific parties of SO268/1+2 and SO242/2 are thanked for their enthusiastic support and assistance in collection of the data used in the current study. We would also like to thank the reviewers for their constructive and helpful comments. 
Funding Open Access funding enabled and organized by Projekt DEAL. This work was funded by the German Ministry of Research and Education (BMBF grant no. 03F0707A-G) as part of the MiningImpact project of the Joint Programming Initiative of Healthy and Productive Seas and Oceans (JPIOceans). The research has also received funding from the European Union Seventh Framework Program (FP7/2007-2013) under the MIDAS project, grant agreement number 603418 . SPR work is supported by FCT/MCTES through the "CEEC Individual 2017" contract (CEECIND/00758/2017) and funds granted to CESAM (UIDP/50017/2020 + UIDB/50017/2020). DC was supported by a fellowship from FCT SFRH/BPD/110278/2015 and "Acores-45-2019-58 Programa Operacional para os Açores 2020". Both CESAM and IMAR received funding through the projects Mining2/0002/2017 and Mining2/0005/2017, granted by FCT/MCTES and Direção-Geral de Politica do Mar (DGPM). Additional funding was provided by the Helmholtz Association's Alfred Wegener Institute.

\section{Declarations}

Conflict of interest The authors declare no competing interests.

Ethical approval No animal testing was performed during this study.

Sampling and field studies All necessary permits for this field study have been obtained by the authors from the competent authorities for the expedition. This non-invasive work in the high seas does not require biological sampling permits.

Data availability The datasets analyzed during the current study are available on the PANGAEA permanent repository (SO242/2 https:// doi.org/10.1594/PANGAEA.890634; SO268/1 + 2 https://doi.pangaea. de/10.1594/PANGAEA.935856) and are described in the cruise reports for SO242/1 and SO242/2 (https://miningimpact.geomar.de/so242/12; jsessionid=BEE2293BAD46016D92C2FB87DF86D1A7), and for SO268/1 + 2 (https://www.ldf.uni-hamburg.de/en/sonne/wochenberi chte/wochenberichte-sonne/so267-2-268-3/so268-scr.pdf).

Author contribution LB and AP conceived and designed the research. $\mathrm{AP}, \mathrm{YM}$ and $\mathrm{AB}$ collected the image data. $\mathrm{AB}$ led the research expedition and designed the image sampling campaign. LB, AP, SPR and DC analyzed the images, compiled data and did the analyses. LB wrote the manuscript with input from all co-authors.

Open Access This article is licensed under a Creative Commons Attribution 4.0 International License, which permits use, sharing, adaptation, distribution and reproduction in any medium or format, as long as you give appropriate credit to the original author(s) and the source, provide a link to the Creative Commons licence, and indicate if changes were made. The images or other third party material in this article are included in the article's Creative Commons licence, unless indicated otherwise in a credit line to the material. If material is not included in the article's Creative Commons licence and your intended use is not permitted by statutory regulation or exceeds the permitted use, you will need to obtain permission directly from the copyright holder. To view a copy of this licence, visit http://creativecommons.org/licenses/by/4.0/.

\section{References}

Auburn FM (1970) Deep Sea Mining. Am Bar Assoc J 56:975-976 Bluhm H (2001) Re-establishment of an abyssal megabenthic community after experimental physical disturbance of the seafloor.
Deep Res Part II 48:3841-3868. https://doi.org/10.1016/S09670645(01)00070-4

Boetius A (2015) RV SONNE Fahrtbericht / Cruise Report SO242-2 [SO242/2]: JPI OCEANS ecological aspects of deep-sea mining, DISCOL revisited, Guayaquil - Guayaquil (Equador), 28.08.01.10.2015. GEOMAR Rep 27. https://doi.org/10.3289/GEOMAR_REP_NS_27_2015

Connolly TP, McGill PR, Henthorn RG, Burrier DA, Michaud C (2020) Near-bottom currents at Station M in the abyssal Northeast Pacific. Deep Res Part II:173. https://doi.org/10.1016/j.dsr2. 2020.104743

De Smet B, Pape E, Riehl T, Bonifácio P, Colson L, Vanreusel A (2017) The community structure of deep-sea macrofauna associated with polymetallic nodules in the eastern part of the ClarionClipperton Fracture Zone. Front Mar Sci 4. https://doi.org/10. 3389/fmars.2017.00103

Durden JM, Simon-Lledó E, Gooday AJ, Jones DOB (2017) Abundance and morphology of Paleodictyon nodosum, observed at the Clarion-Clipperton Zone. Mar Biodivers 47:265-269. https://doi. org/10.1007/s12526-017-0636-0

Ehrlich H (2019) Paleodyction - Enigmatic Honeycomb Structure. In: Marine Biological Materials of Invertebrate Origin. Springer International Publishing AG, pp 81-86. https://doi.org/10.1007/ 978-3-319-92483-0_6

Ekdale AA (1980) Graphoglyptid burrows in modern deep-sea sediment. Science 207:304-306. https://doi.org/10.1126/science.207. 4428.304

Gaillard C (1991) Recent organism traces and ichnofacies on the deepsea floor off New Caledonia, southwestern Pacific. Soc Sediment Geol 6:302-315. https://doi.org/10.2307/3514910

Garlick GD, Miller WC (1993) Simulations of burrowing strategies and construction of Paleodictyon. J Geol Educ 41:159-163. https:// doi.org/10.5408/0022-1368-41.2.159

Gollner S, Kaiser S, Menzel L et al (2017) Resilience of benthic deepsea fauna to mining activities. Mar Environ Res 129:76-101. https://doi.org/10.1016/j.marenvres.2017.04.010

Gooday AJ, Bett BJ, Pratt DN (1993) Direct observation of episodic growth in an abyssal xenophyophore (Protista). Deep Res Part I 40:2131-2143. https://doi.org/10.1016/0967-0637(93)90094-J

Grassle JF (1977) Slow recolonisation of deep-sea sediment. Nature 265:618-619. https://doi.org/10.1038/265618a0

Greinert J (2015) RV SONNE Fahrtbericht/ Cruise Report SO242-1 [SO242/1]: JPI OCEANS Ecological Aspects of Deep-Sea Mining - DISCOL Revisited, Guayaquil - Guayaquil (Equador), 28.07. - 25.08.2015. GEOMAR Rep 26. https://doi.org/10.3289/GEOMAR_REP_NS_26_2015

Haffert L, Haeckel M, De Stigter H, Janssen F (2020) DISCOL experiment revisited: Assessing the temporal scale of deep-sea mining impacts on sediment biogeochemistry. Biogeosciences 17:27672789. https://doi.org/10.5194/bg-17-2767-2020

Hein JR, Koschinsky A (2013) Deep-ocean ferromanganese crusts and nodules. In: Holland H, Turekian K (eds) Earth Systems and Environmental Sciences, Treatise on Geochemistry 2nd Edition, 2nd edn. Elsevier, Amsterdam, pp 273-291. https://doi.org/10.1016/ B978-0-08-095975-7.01111-6

Hein JR, Mizell K, Koschinsky A, Conrad TA (2013) Deep-ocean mineral deposits as a source of critical metals for high- and greentechnology applications: comparison with land-based resources. Ore Geol Rev 51:1-14. https://doi.org/10.1016/j.oregeorev.2012. 12.001

Jankowski JA, Zielke W (2001) The mesoscale sediment transport due to technical activities in the deep sea. Deep Res Part II 48:34873521. https://doi.org/10.1016/S0967-0645(01)00054-6

Jones DOB, Kaiser S, Sweetman AK, et al (2017) Biological responses to disturbance from simulated deep-sea polymetallic nodule mining. PLoS One 12. https://doi.org/10.1371/journal.pone.0171750 
Kern JP (1978) Trails from the Vienna Woods: Paleoenvironments and trace fossils of Cretaceous to Eocene flysch, Vienna, Austria. Palaeogeogr Palaeoclimatol Palaeoecol 23:231-262. https://doi. org/10.1016/0031-0182(78)90095-0

Kuhn T, Uhlenkott K, Vink A, Rühlemann C, Martinez Arbizu P (2020) Manganese nodule fields from the Northeast Pacific as benthic habitats. In: Harris PT, Baker E (eds) Seafloor Geomorphology as Benthic Habitat, 2nd edn. Elsevier, pp 933-947. https://doi.org/ 10.1016/B978-0-12-814960-7.00058-0

Kuhn T, Wegorzewski A, Rühlemann C, Vink A (2017) Composition, Formation, and occurrence of polymetallic nodules. In: Sharma R (ed) Deep-Sea Mining. Springer, Cham, pp 23-63. https://doi. org/10.1007/978-3-319-52557-0_2

Kushlin BK (1982) On the algal nature of Paleodictyon. Int Geol Rev 24:269-278. https://doi.org/10.1080/00206818209452403

Langenkämper D, Zurowietz M, Schoening T, Nattkemper TW (2017) BIIGLE 2.0 - browsing and annotating large marine image collections. Front Mar Sci 4:1-10. https://doi.org/10.3389/fmars.2017. 00083

Levin LA (1994) Paleoecology and ecology of xenophyophores. Palaios 9:32-41. https://doi.org/10.2307/3515076

Linke P, Haeckel M (2019) Short Cruise Report RV SONNE SO268/1+2 Manzanillo - Manzanillo - Vancouver 17.02.2019 $-27.05 .2019$

Malekzadeh M, Wetzel A (2020) Paleodictyon in shallow-marine settings - an evaluation based on eocene examples from Iran. Palaios 35:377-390. https://doi.org/10.2110/PALO.2020.030

Marchig V, Von Stackelberg U, Hufnagel H, Durn G (2001) Compositional changes of surface sediments and variability of manganese nodules in the Peru Basin. Deep Res Part II 48:3523-3547. https:// doi.org/10.1016/S0967-0645(01)00055-8

Marcon Y, Purser A (2017) PAPARA(ZZ)I: An open-source software interface for annotating photographs of the deep-sea. SoftwareX 6:69-80. https://doi.org/10.1016/j.softx.2017.02.002

Martínez Arbizu P, Haeckel M (2015) RV SONNE Fahrtbericht / Cruise Report SO239: EcoResponse assessing the ecology, connectivity and resilience of polymetallic nodule field systems, Balboa (Panama) - Manzanillo (Mexico) 11.03.-30.04.2015. GEOMAR Rep 25. https://doi.org/10.3289/GEOMAR_REP_NS_25_ 2015

Miljutin DM, Miljutina MA, Martínez Arbizu P, Galéron J (2011) Deep-sea nematode assemblage has not recovered 26 years after experimental mining of polymetallic nodules (Clarion-Clipperton Fracture Zone, Tropical Eastern Pacific). Deep Res Part I 58:885897. https://doi.org/10.1016/j.dsr.2011.06.003

Molari M, Janssen F, Vonnahme TR, Wenzhöfer F, Boetius A (2020) The contribution of microbial communities in polymetallic nodules to the diversity of the deep-sea microbiome of the Peru Basin (4130-4198m depth). Biogeosciences 17:3203-3222. https://doi. org/10.5194/bg-17-3203-2020

Plotnick RE (2003) Ecological and L-system based simulations of trace fossils. Palaeogeogr Palaeoclimatol Palaeoecol 192:45-58. https:// doi.org/10.1016/S0031-0182(02)00678-8

Przeslawski R, Dundas K, Radke L, Anderson TJ (2012) Deep-sea Lebensspuren of the Australian continental margins. Deep Res I 65:26-35. https://doi.org/10.1016/j.dsr.2012.03.006

Purser A, Marcon Y, Dreutter S et al (2019) Ocean Floor Observation and Bathymetry System (OFOBS): a new towed camera/sonar system for deep-sea habitat surveys. IEEE J Ocean Eng 44:87-99. https://doi.org/10.1109/JOE.2018.2794095

Purser A, Marcon Y, Hoving HJT, Vecchione M, Piatkowski U, Eason D, Bluhm H, Boetius A (2016) Association of deep-sea incirrate octopods with manganese crusts and nodule fields in the Pacific Ocean. Curr Biol 26:R1268-R1269. https://doi.org/10.1016/j.cub. 2016.10.052
Radziejewska T (2002) Responses of deep-sea meiobenthic communities to sediment disturbance simulating effects of polymetallic nodule mining. Int Rev Hydrobiol 87:457-477. https://doi.org/ 10.1002/1522-2632(200207)87:4\%3c457::AID-IROH457\%3e3.0. $\mathrm{CO} ; 2-3$

Rona PA, Merrill GF (1978) A benthic invertebrate from the midAtlantic ridge. Bull Mar Sci 28:371-375

Rona PA, Seilacher A, de Vargas C et al (2009) Paleodictyon nodosum: a living fossil on the deep-sea floor. Deep Res II 56:1700-1712. https://doi.org/10.1016/j.dsr2.2009.05.015

Schoening T, Purser A, Langenkämper D et al (2020) Megafauna community assessment of polymetallic-nodule fields with cameras: platform and methodology comparison. Biogeosciences 17:31153133. https://doi.org/10.5194/bg-17-3115-2020

Schriever G, Thiel H, Beckmann W, et al (1992) Cruise report DISCOL 3, SONNE cruise 77 : Cruise report DISCOL 3, Sonne cruise 77 : January 26 - February 27, 1992, Balboa/Panama-Balboa/Panama. Berichte aus dem Zentrum für Meeres- und Klimaforschung : Reihe E, Hydrobiologie und Fischereiwissenschaft Nr. 2 : DISCOL publication, No. 20:59 pp

Seilacher A (2007) Deepsea farmers. In: Trace Fossil Analysis. Springer, Berlin, Heidelberg, pp 156-158. https://doi.org/10.1007/978-3-54047226-1_11

Simon-Lledó E, Bett BJ, Huvenne VAI, Köser K, Schoening T, Greinert J, Jones DOB (2019) Biological effects 26 years after simulated deep-sea mining. Sci Rep 9:1-13. https://doi.org/10.1038/s41598-019-44492-w

Swinbanks DD (1982) Paleodictyon: the traces of infaunal xenophyophores? Science 218:47-50. https://doi.org/10.1126/science.218. 4567.47

Thiel H (2001) Evaluation of the environmental consequences of polymetallic nodule mining based on the results of the TUSCH Research Association. Deep Res Part II 48:3433-3452. https://doi.org/10.1016/ S0967-0645(01)00051-0

Thiel H, Schriever G (1990) Deep-sea mining, environmental impact and the DISCOL project. Ambio 19:245-250

Uchman A (2003) Trends in diversity, frequency and complexity of graphoglyptid trace fossils: evolutionary and palaeoenvironmental aspects. Palaeogeogr Palaeoclimatol Palaeoecol 192:123-142. https://doi.org/ 10.1016/S0031-0182(02)00682-X

Uchman A (2004) Phanerozoic history of deep-sea trace fossils. In: McIlroy D (ed) The application of ichnology to palaeoenvironmental and stratigraphic analysis. Geological Society, Special Publications, London, pp 125-139. https://doi.org/10.1144/GSL.SP.2004.228.01.07

Vanreusel A, Hilario A, Ribeiro PA, Menot L, Martínez Arbizu P (2016) Threatened by mining, polymetallic nodules are required to preserve abyssal epifauna. Sci Rep 6:1-6. https://doi.org/10.1038/srep26808

Vonnahme TR, Molari M, Janssen F, Wenzhöfer F, Haeckel M, Titschack J, Boetius A (2020) Effects of a deep-sea mining experiment on seafloor microbial communities and functions after 26 years. Sci Adv 6: https:// doi.org/10.1126/sciadv.aaz5922

Washburn TW, Menot L, Bonifácio P et al (2021) Patterns of Macrofaunal Biodiversity Across the Clarion-Clipperton Zone: An Area Targeted for Seabed Mining. Front Mar Sci 8:1-22. https://doi.org/10.3389/ fmars.2021.626571

Wetzel A (2000) Giant Paleodictyon in Eocene flysch. Palaeogeogr Palaeoclimatol Palaeoecol 160:171-178. https://doi.org/10.1016/ S0031-0182(00)00064-X

Wheatcroft RA, Smith CR, Jumars PA (1989) Dynamics of surficial trace assemblages in the deep sea. Deep Sea Res 36:71-91. https:// doi.org/10.1016/0198-0149(89)90019-8

Publisher's note Springer Nature remains neutral with regard to jurisdictional claims in published maps and institutional affiliations. 